\title{
Exercise duration-matched interval and continuous sprint cycling induce similar increases in AMPK phosphorylation, PGC-1 $\alpha$ and VEGF mRNA expression in trained individuals
}

\author{
Conor W. Taylor ${ }^{1,2,3} \cdot$ Stephen A. Ingham ${ }^{2} \cdot J^{2}$ lie E. A. Hunt ${ }^{1,4} \cdot$ Neil R. W. Martin $^{1} \cdot$ \\ Jamie S. M. Pringle ${ }^{2,5}$ - Richard A. Ferguson ${ }^{1}$
}

Received: 19 February 2016 / Accepted: 19 May 2016 / Published online: 1 June 2016

(C) The Author(s) 2016. This article is published with open access at Springerlink.com

\begin{abstract}
Purpose The effects of low-volume interval and continuous 'all-out' cycling, matched for total exercise duration, on mitochondrial and angiogenic cell signalling was investigated in trained individuals.

Methods In a repeated measures design, 8 trained males $\left(\dot{V} \mathrm{O}_{2 \text { peak }}, 57 \pm 7 \mathrm{ml} \mathrm{kg} \mathrm{min}^{-1}\right)$ performed two cycling exercise protocols; interval (INT, $4 \times 30 \mathrm{~s}$ maximal sprints interspersed by 4 min passive recovery) or continuous (CON, 2 min continuous maximal sprint). Muscle biopsies were obtained before, immediately after and $3 \mathrm{~h}$ post-exercise.

Results Total work was $53 \%$ greater $(P=0.01)$ in INT compared to CON $(71.2 \pm 7.3$ vs. $46.3 \pm 2.7 \mathrm{~kJ}$, respectively). Phosphorylation of $\mathrm{AMPK}^{\mathrm{Thr} 172}$ increased by a similar magnitude $(P=0.347)$ immediately post INT
\end{abstract}

Communicated by Anni Vanhatalo.

Richard A. Ferguson

R.Ferguson@lboro.ac.uk

1 School of Sport, Exercise and Health Sciences, Loughborough University, Loughborough, Leicestershire LE11 3TU, UK

2 English Institute of Sport, EIS Performance Centre, Loughborough University, Loughborough LE11 3TU, UK

3 Present Address: English Institute of Sport, Manchester Institute of Health and Performance, 299 Alan Turing Way, Manchester M11 3BS, UK

4 Present Address: Faculty of Health and Medical Sciences, School of Biosciences and Medicine, University of Surrey, Guildford GU2 7YW, UK

5 Present Address: British Athletics, National Performance Institute, Loughborough University, Loughborough LE11 3TU, UK and CON (1.6 \pm 0.2 and $1.3 \pm 0.3$ fold, respectively; $P=0.011$ ), before returning to resting values at $3 \mathrm{~h}$ postexercise. mRNA expression of PGC-1 $\alpha$ (7.1 \pm 2.1 vs. $5.5 \pm 1.8$ fold; $P=0.007)$, VEGF (3.5 \pm 1.2 vs. $4.3 \pm 1.8$ fold; $P=0.02)$ and HIF- $1 \alpha(2.0 \pm 0.5$ vs. $1.5 \pm 0.3$ fold; $P=0.04)$ increased at $3 \mathrm{~h}$ post-exercise in response to INT and $\mathrm{CON}$, respectively; the magnitude of which were not different between protocols.

Conclusions Despite differences in total work done, lowvolume INT and CON 'all-out' cycling, matched for exercise duration, provides a similar stimulus for the induction of mitochondrial and angiogenic cell signalling pathways in trained skeletal muscle.

Keywords Angiogenesis · HIF-1 $\alpha \cdot$ High-intensity training $\cdot$ Mitochondrial biogenesis $\cdot$ Sprint interval exercise

$\begin{array}{ll}\text { Abbreviations } \\ \text { AMP } & \text { Adenosine monophosphate } \\ \text { AMPK } & \begin{array}{l}\text { Adenosine monophosphate-activated protein } \\ \text { kinase }\end{array} \\ \text { ACC } & \text { Phospho-acetyl-CoA carboxylase } \\ \text { ATP } & \text { Adenosine triphosphate } \\ \text { CON } & \text { Continuous-based 'all-out' cycling protocol } \\ \text { eNOS } & \text { Endothelial nitric oxide synthase } \\ \text { HIF-1 } \alpha & \text { Hypoxia inducible factor 1 alpha subunit } \\ \text { INT } & \text { Interval-based 'all-out' cycling protocol } \\ \text { MAP } & \text { Maximal aerobic power } \\ \text { MPO } & \text { Mean power output } \\ \text { MMP-9 } & \text { Matrix metalloproteinase 9 } \\ \text { mRNA } & \text { Messenger RNA } \\ \text { PGC-1 } \alpha & \text { Peroxisome proliferator-activated } \gamma \text { receptor } \\ & \text { coactivator 1 alpha subunit } \\ \text { PPO } & \text { Peak power output }\end{array}$


RNA Ribonucleic acid

RT-PCR Real time polymerase chain reaction

SIT Sprint interval training

SE Standard error

VEGF Vascular endothelial growth factor

$\dot{V} \mathrm{O}_{2 \text { peak }} \quad$ Peak oxygen uptake

\section{Introduction}

Low-volume sprint interval training (SIT), typically comprising 4-6 × $30 \mathrm{~s}$ 'all-out' efforts interspersed by $4 \mathrm{~min}$ of recovery, has proven as effective as traditional, high-volume endurance training (e.g. $>40 \mathrm{~min}$ continuous moderate intensity training) in increasing muscle oxidative potential, buffering capacity, resting muscle glycogen content and muscle capillarity (Gibala et al. 2006; Burgomaster et al. 2008; Cocks et al. 2013). This time-efficient training model presents health benefits for sedentary and clinical populations and a potentially potent stimulus for enhancing athletic performance. Indeed, endurance athletes are typically accustomed to high-volume training methods, and thus, novel work- and time- efficient exercise stimuli to further enhance training adaptation are desirable.

The underlying factors responsible for the comparable skeletal muscle re-modelling and exercise performance after SIT and high-volume endurance training remain unclear (Baar et al. 2002; Pilegaard et al. 2003; Lee-young et al. 2009; Gibala et al. 2009). In addition to differences in the initial fitness levels of the aforementioned study cohorts and differences in total work done, exercise duration and intensity, the interval nature of SIT is a distinguishing factor between the training protocols prescribed. Recent studies (Bartlett et al. 2012; Cochran et al. 2014) have examined the effects of this 'pulsatile' exercise pattern on the acute activation of cell signalling cascades that if repeatedly stressed over time, regulate endurance based skeletal muscle adaptations and in particular mitochondrial biogenesis (Perry et al. 2010).

In this regard, homeostatic perturbations within skeletal muscle (e.g. increased AMP/ATP ratios and reductions in muscle glycogen) phosphorylate and activate protein kinases, such as the adenosine monophosphate-activated protein kinase (AMPK). Upon activation, AMPK converges on the cell nucleus and is implicated in the regulation of peroxisome proliferator-activated $\gamma$ receptor coactivator (PGC-1 $\alpha$ ) (Jäger et al. 2007; Cantó and Auwerx 2010). Via interactions with downstream transcription factors and nuclear receptors, PGC- $1 \alpha$ is considered to play a "master" regulatory role in exercise-induced mitochondrial biogenesis (Puigserver and Spiegelman 2003) and angiogenesis through an interaction with vascular endothelial growth factor (VEGF) (Leick et al. 2009;
Chinsomboon et al. 2009; Geng et al. 2010). Indeed, similar increases in AMPK phosphorylation and PGC- $1 \alpha$ mRNA expression have been observed after work/duration-matched $(\sim 50 \mathrm{~min})$ interval and continuous highintensity running in recreationally active men (Bartlett et al. 2012). More recently, a study by Cochran and colleagues (Cochran et al. 2014) observed similar increases in acetyl-CoA carboxylase (ACC) phosphorylation (a surrogate marker of AMPK activation) and PGC- $1 \alpha$ mRNA expression in response to work-matched SIT and maximal continuous ( 4 min) cycling. However, whilst acute SIT has previously been shown to increase upstream genetic markers of mitochondrial biogenesis in both recreationally active individuals (Gibala et al. 2009) and 'elite level' cyclists (Psilander et al. 2010), its effects on regulators of exercise-induced angiogenesis (e.g. VEGF, HIF-1 $\alpha$, eNOS, MMP-9) have not been reported in untrained or trained muscle.

Since work done and the pattern of exercise (i.e. interval vs. continuous) have previously been demonstrated to have little effect on acute cell signalling responses, it was hypothesised that despite differing in total work done, brief 'all-out' cycling, be it repeated intervals or a continuous single effort, would induce similar increases in cell signalling cascades linked to mitochondrial biogenesis and angiogenesis in trained skeletal muscle.

\section{Methods}

\section{Participants}

Eight healthy males (mean \pm SD: age, $30 \pm 5 \mathrm{yr}$; stature, $180 \pm 9 \mathrm{~cm}$; body mass, $79 \pm 11 \mathrm{~kg}$; PPO, $16 \pm 2 \mathrm{~W} . \mathrm{kg}$; $\dot{V} \mathrm{O}_{2 \text { peak }}, 4.5 \pm 0.5 \mathrm{~L} \mathrm{~min}^{-1} ; 57 \pm 7 \mathrm{ml} \mathrm{kg}^{-1} \mathrm{~min}^{-1}$; MAP, $347 \pm 27 \mathrm{~W}$ ) volunteered to take part in the investigation. All were involved in cycling activities three to six times per week and on at least one occasion per week also performed resistance training consisting of lower body bilateral compound exercises (e.g. squats, Olympic lifting). Although all participants had previous experience of undertaking highintensity training, none were engaging in this type of training during the study period. Participants completed a medical questionnaire and biopsy screening document prior to participation to mitigate for maximal exercise and biopsy contraindications. Participants did not have a history of neuromuscular, haematological or musculoskeletal abnormalities or were using pharmacological treatments during the study period. The participants were fully informed of the purposes, risks and discomforts associated with the investigation before providing written consent. The investigation conformed to current local guidelines and the Declaration of Helsinki and was approved by the Ethics Approval 
(Human Participants) Sub-Committee of the Loughborough University Ethical Advisory Committee.

\section{Experimental design}

In a fully randomised, repeated measures crossover design, participants performed 'all-out' interval (INT) or continuous (CON) cycling protocols, which were separated by 14-21 days. Muscle biopsies were obtained before, immediately and $3 \mathrm{~h}$ post-exercise. Participants recorded all food consumed and physical activity performed during the $24 \mathrm{~h}$ prior to their first experimental trial and were instructed to replicate these dietary and activity patterns prior to their second experimental trial as well as refrain from ingesting alcohol and caffeine containing substances during the $48 \mathrm{~h}$ preceding each trial. Participants were instructed to arrive at the laboratory by identical means of travel for both experimental trials. All arrived by car and made a short walk to the ground floor laboratory in which all testing took place (i.e. very minimal work was performed in getting to the laboratory). All cycle protocols were performed on an SRM ergometer (Schroberer Rad McBtechink, Weldorf, Germany) calibrated according to the manufacturer guidelines.

\section{Preliminary testing}

Two weeks prior to the first experimental trial, participants were reported to the laboratory on three occasions, separated by at least 3 days to complete preliminary measurements and protocol familiarisation. During the first visit optimal pedal cadence for peak power output (PPO) was determined by performing maximal sprints $(<12 \mathrm{~s})$ at multiple fixed cadences. The optimal pedal cadence, defined as the zenith of the cadence-peak power relationship, was subsequently used as the fixed (isokinetic) cadence for the subsequent experimental trials. A maximal incremental cycle test was also performed during this visit to establish peak oxygen uptake $\left(\dot{V} \mathrm{O}_{\text {2peak }}\right)$ and maximal aerobic power (MAP) to establish aerobic training status. Following a 5 min warm-up at $120 \mathrm{~W}$, at a freely chosen but constant pedal cadence, work rate was increased by $20 \mathrm{~W}$ every $60 \mathrm{~s}$ until volitional exhaustion (8-10 min). Pulmonary gas exchange was measured breath by breath throughout exercise (Oxycon Pro, Carefusion, UK) and $\dot{V} \mathrm{O}_{2 \text { peak }}$ determined as the highest $30 \mathrm{~s}$ recording of $\dot{V} \mathrm{O}_{2}$ during the test. MAP was defined as the highest average $60 \mathrm{~s}$ power recorded during the test. On the two subsequent visits participants performed familiarisation trials during which they performed the INT and CON protocols. The cycle ergometer saddle and handlebar configuration was consistent for each participant during all exercise testing.

\section{Experimental protocols}

Participants attended the laboratory in the morning $(\sim 0800 \mathrm{~h})$ of each experimental trial following an overnight fast. On arrival, participants rested in a supine position for 20 min whilst the muscle biopsy sites were prepared. After a resting muscle biopsy was taken, participants performed a standardised warm-up, consisting of cycling at $120 \mathrm{~W}$ for 5 min, immediately after which they performed either the INT or CON cycling trials. The INT protocol consisted of $4 \times 30 \mathrm{~s}$ 'all-out' efforts at the predetermined fixed (isokinetic) pedal cadence. Each bout was interspersed by $4 \mathrm{~min}$ of recovery during which participants remained seated on the cycle ergometer and were permitted to cycle at a cadence of $\sim 60$ revs $\min ^{-1}$ against a resistance of $<20 \mathrm{~W}$. This resulted in total session duration of $14 \mathrm{~min}$, excluding the 5 min warm-up. The CON protocol consisted of a single 2 min bout of continuous 'all-out' cycling at the same isokinetic pedal cadence. To ensure each protocol was performed in an 'all-out' manner, participants were verbally instructed and encouraged before commencing and during each protocol to attain PPO within the first few seconds of each exercise bout and apply maximal force through the pedals until the end of each exercise bout. Immediately after both protocols, participants quickly dismounted the ergometer and were helped onto an adjacent couch where the immediate post-exercise muscle biopsy was taken within 1 min of the cessation of each protocol. During this time, a finger-prick capillary blood sample was obtained every consecutive minute, and immediately analysed for lactate concentration (Biosen HBAC1 Analyser, EKF Diagnostics, UK) until a peak lactate concentration was determined (within 10-15 min). Participants then rested before a final muscle biopsy was taken $3 \mathrm{~h}$ post-exercise. Biopsies for a given trial were obtained from the same leg through separate incisions $\sim 3 \mathrm{~cm}$ apart. In the subsequent experimental trial, biopsies were obtained from the alternate leg in a randomised, crossover fashion to avoid any potential order bias. The consumption of food was prohibited at all times during each experimental trial. Water was consumed freely but the volume and pattern ingested was noted during the first trial and replicated for the subsequent trial. Laboratory conditions remained constant for both experimental trials $\left(19-21^{\circ} \mathrm{C}, 40-50 \%\right.$ humidity).

Power output during preliminary testing and both experimental protocols were sampled at $0.5 \mathrm{~Hz}$ and analysed using SRM software (v6.40.05, Schoberer Rad Messtechnik, Germany) which was calibrated before each trial by recording the zero offset without any force/load on the cranks. Peak power output (PPO) was defined as the highest single power output value recorded during each sprint. Mean power output (MPO) was defined as the average 
value of all measures of power output throughout each sprint.

\section{Muscle biopsy sampling and analysis}

Muscle biopsies were obtained from the medial portion of the vastus lateralis muscle under local anaesthesia $(1 \%$ lidocaine) using the micro-biopsy technique (Acecut $11 \mathrm{G}$ Biopsy Needle, TSK). Muscle samples at each time point were obtained through separate incisions with two samples (each $\sim 25 \mathrm{mg}$ ) being taken from each incision.

\section{Western blot analysis}

Approximately $20 \mathrm{mg}$ of frozen muscle was ground to powder under liquid nitrogen using a laboratory grade pestle and mortar before being homogenised in $120 \mu \mathrm{l}$ of ice cold lysis buffer (25 mM Tris/HCl [pH 7.4], $50 \mathrm{mM} \mathrm{NaF}$, $100 \mathrm{mM} \mathrm{NaCl}, 5 \mathrm{mM}$ EGTA, $1 \mathrm{mM}$ EDTA, $10 \mathrm{mM}$ NaPyrophosphatase, $1 \mathrm{mM} \mathrm{Na}_{3} \mathrm{VO}_{4}, 0.27 \mathrm{M}$ sucrose, $1 \%$ Triton X-100, $0.1 \%$ 2-mercaptoethanol) supplemented with a Pierce ${ }^{\mathrm{TM}}$ Protease Inhibitor Tablet (Thermo Scientific, UK). Homogenates were centrifuged at $13,500 \mathrm{~g}$ for $10 \mathrm{~min}$ at $4{ }^{\circ} \mathrm{C}$ and the supernatant collected. Protein content of the supernatant was determined using a Pierce ${ }^{\mathrm{TM}} 660$ Protein Assay (Thermo Scientific, UK). Each sample was solubilized for $5 \mathrm{~min}$ at $100{ }^{\circ} \mathrm{C}$ with an equal volume of sample buffer containing $1 \mathrm{M}$ Tris- $\mathrm{HCl}(\mathrm{pH} 6.8), 8 \%$ glycerol, $10 \%$ sodium dodecyl sulphate, $0.4 \% 2-\beta$-mercaptoethanol and $0.05 \%$ bromophenol blue. For each blot a negative control was loaded along with $25 \mu \mathrm{g}$ of each sample and then separated $(\sim 100 \mathrm{~V}$ for $\sim 2 \mathrm{~h})$ in Tris-glycine running buffer using self-cast $4 \%$ stacking and $10 \%$ separating polyacrylamide gels. Gels were transferred wet onto nitrocellulose membranes for $2 \mathrm{~h}$ at $35 \mathrm{~mA}$ in a $1 \times$ transfer buffer $(0.3 \%$ Tris base, $1.4 \%$ glycine, $20 \%$ methanol). Membranes were then blocked for $1 \mathrm{~h}$ at room temperature in Tris-buffered saline (TBST: 0.19 M Tris [pH 7.6], $1.3 \mathrm{M}$ $\mathrm{NaCl}, 0.1 \%$ Tween-20) with $5 \%$ non-fat blocking grade milk. Membranes were washed for $3 \times 5 \mathrm{~min}$ in TBST before being incubated overnight at $4{ }^{\circ} \mathrm{C}$ with anti-phos-

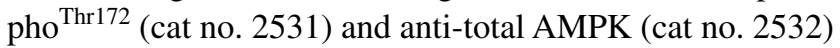
antibody (both from cell signalling, UK), at a concentration of 1:1000 in $1 \times$ TBST. The following morning, membranes were washed for a further $3 \times 5 \mathrm{~min}$ in TBST, and subsequently incubated with anti-species horseradish peroxidase-conjugated secondary antibody (Bio-Rad, UK) for $1 \mathrm{~h}$ at room temperature. After a further $3 \times 5$ min washes in TBST, membranes were saturated in chemiluminescence (SuperSignal, Thermo Fisher Scientific, Rockford, IL, USA) for $5 \mathrm{~min}$ prior to exposure. Membranes were visualised using image analysis (ChemiDoc ${ }^{\mathrm{TM}} \mathrm{XRS}+$, BioRad, Herts, UK), and band densities determined (Quality
Table 1 Primers used for real-time RT-PCR analyses

\begin{tabular}{|c|c|c|c|}
\hline \multicolumn{2}{|c|}{ Target gene } & \multirow{2}{*}{$\begin{array}{l}\text { Primer sequence } \\
\text { CTGCTCTACCTCCACCAT } \\
\text { ATGAACTTCA } \\
\text { CCACTTCGT }\end{array}$} & \multirow{2}{*}{$\frac{\text { No. in gene bank }}{\text { NM_001171630 }}$} \\
\hline VEGF & $\begin{array}{l}\text { Forward } \\
\text { Reverse }\end{array}$ & & \\
\hline PGC-1 $\alpha$ & $\begin{array}{l}\text { Forward } \\
\text { Reverse }\end{array}$ & $\begin{array}{l}\text { CCTCTTCAAGATCC } \\
\text { TGCTA } \\
\text { ACTCTCGCTTCTCA } \\
\text { TACTC }\end{array}$ & NM_013261 \\
\hline eNOS & $\begin{array}{l}\text { Forward } \\
\text { Reverse }\end{array}$ & $\begin{array}{l}\text { CAAGTTGGAATCTCG } \\
\text { TGAA } \\
\text { TGTGAAGGCTGTAGG } \\
\text { TTAT }\end{array}$ & NM_001160111 \\
\hline MMP-9 & $\begin{array}{l}\text { Forward } \\
\text { Reverse }\end{array}$ & $\begin{array}{l}\text { GGCACCTCTATGGTCCTC } \\
\text { AGTAGTGGCCGT } \\
\text { AGAAGG }\end{array}$ & NM_004994 \\
\hline HIF-l $\alpha$ & $\begin{array}{l}\text { Forward } \\
\text { Reverse }\end{array}$ & $\begin{array}{l}\text { TCACCTGAGC- } \\
\text { CTAATAGTC } \\
\text { AATCTGTGTCCTGAGT } \\
\text { AGAA }\end{array}$ & NM_181054 \\
\hline RPII & $\begin{array}{l}\text { Forward } \\
\text { Reverse }\end{array}$ & $\begin{array}{l}\text { GAGTCAACGGATTT } \\
\text { GGTC } \\
\text { GGTGGAATCATATT } \\
\text { GGAACAT }\end{array}$ & NM_000938.1 \\
\hline
\end{tabular}

$V E G F$ vascular endothelial growth factor, $P G C$ - $l \alpha$ peroxisome proliferator-activated receptor $\gamma$ coactivator-l $\alpha, e N O S$ endothelial nitric oxide synthase, MMP-9 membrane metalloproteinase-9, HIF-l $\alpha$ hypoxic inducible factor-l $\alpha, R P I I$ RNA polymerase II

One 1-D analysis software v 4.6.8, Bio-Rad, Herts, UK). Samples from each participant for both exercise protocols were run on the same gel and all gels were run in duplicate to verify responses. Pre-exercise values of phosphorylation relative to total for each participant were normalised to 1 with post-exercise and $3 \mathrm{~h}$ post-exercise values subsequently expressed as fold change relative to pre-exercise values.

\section{Real-time RT-PCR}

One-step quantitative RT-PCR was used to determine skeletal muscle mRNA levels of genes of interest. Primer sequences (Table 1) were designed by Sigma-Aldrich (Sigma-Aldrich Co. Ltd., Haverhill, UK) ideally with 40-60 \% GC content and spanning exon-exon boundaries. Primer specificity was determined by performing BLAST and melt curve analysis at the end of each PCR run. Total RNA was isolated from muscle tissue using TRIzol ${ }^{\circledR}$ according to the manufacturer's instructions (Life Technologies/Invitrogen, USA). Briefly, once the tissue $(\sim 25 \mathrm{mg})$ was homogenised in TRIzol ${ }^{\circledR}$, chloroform $(1: 5 \mathrm{v} / \mathrm{v})$ was added followed by RNA precipitation using isopropanol. The resultant RNA pellet was washed in $75 \%$ absolute ethanol and air dried prior to resuspension in $50 \mu \mathrm{L}$ of $1 \mathrm{mM}$ sodium citrate. RNA concentration $\left(232 \pm 73 \mathrm{ng} \mathrm{\mu l}^{-1}\right)$ and purity (260/280: $1.9 \pm 0.1$ ) was confirmed using 
Fig. 1 MPO achieved for each of the $4 \times 30 \mathrm{~s}$ 'all-out' sprints during INT (a) compared to the MPO achieved in each consecutive $30 \mathrm{~s}$ period of the continuous $2 \mathrm{~min}$ 'all-out' effort in $\mathrm{CON}$ (b)
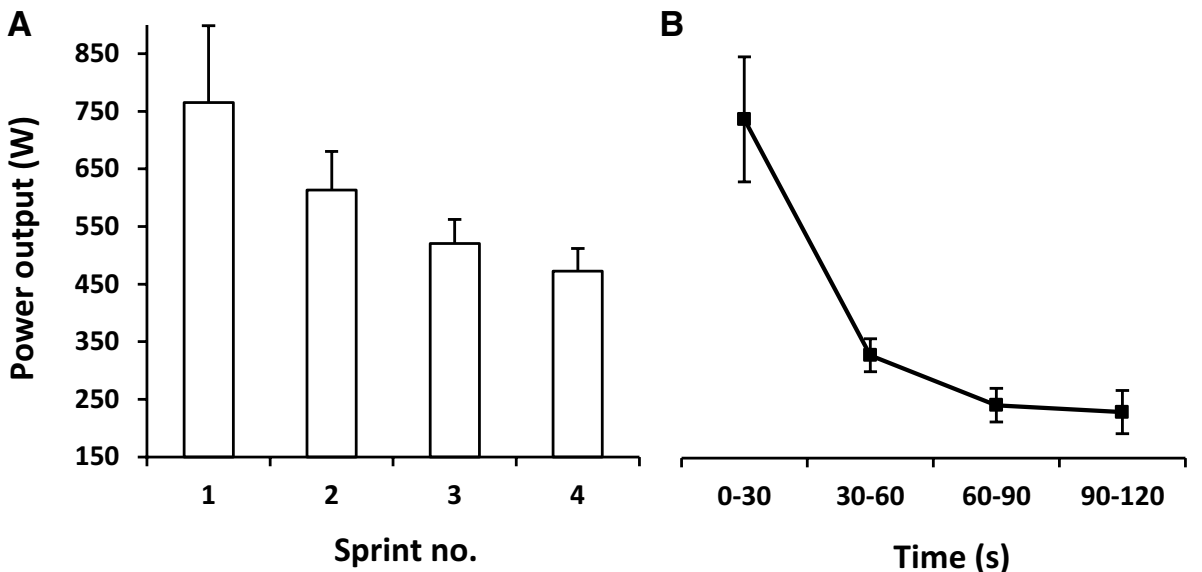

spectrophotometry (Nanodrop) before being stored at $-80{ }^{\circ} \mathrm{C}$ for future use. $20 \mu \mathrm{l}$ PCR reactions were made up as follows in a 96 well plate; $70 \mathrm{ng}$ of RNA in $9.5 \mu \mathrm{l}$ of nuclease free water, $0.2 \mu \mathrm{l}$ of Quantifast Reverse Transcriptase mix (Qiagen, Crawley, UK), $0.15 \mu \mathrm{l}$ of both forward and reverse primers at $100 \mu \mathrm{M}$ concentrations, and $10 \mu \mathrm{l}$ of SYBR green mix (Qiagen). All reactions were performed in triplicate. Once PCR plates were prepared, they were transferred to the $\mathrm{mx} 3005 \mathrm{p}$ qPCR cycler (Stratagene MX3005P, Agilent Technologies, Berkshire, UK), which was programmed to perform the following steps; $50{ }^{\circ} \mathrm{C}$ for $10 \mathrm{~min}$ (reverse transcription), followed by a 5 min hold at $95^{\circ} \mathrm{C}$, and then 40 cycles at $95{ }^{\circ} \mathrm{C}$ for $10 \mathrm{~s}$ and $60{ }^{\circ} \mathrm{C}$ for $30 \mathrm{~s}$. Fluorescence was detected at the end of each cycle, and expression levels were determined using the $2^{-\Delta \Delta C t}$ method using RNA polymerase II (RPII) as the reference gene. The mRNA expression was calculated according to Livak and Schmittgen (2001). Post-exercise values are reported as a fold change relative to pre-exercise values for each individual participant as described previously (Pilegaard et al. 2000; Psilander et al. 2010).

\section{Statistical analysis}

Protein phosphorylation and mRNA data were analysed using a two-way ANOVA. Where significant main effects were observed, Bonferroni corrected post hoc t-tests were used to locate differences. Student's $t$ test for paired samples was also used to compare differences in physiological and performance variables between protocols. All data are presented as mean \pm SE. Significance was accepted at $P<0.05$.

\section{Results}

\section{Physiological and performance variables}

The optimal cadence for PPO was $118 \pm 5$ revs $\min ^{-1}$. There was no difference $(P=0.93)$ in PPO attained during
INT and CON (1217 \pm 257 vs. $1215 \pm 201 \mathrm{~W}$, respectively). However, there was a greater MPO (Fig. 1) during INT compared to CON (593 \pm 61 vs. $386 \pm 23 \mathrm{~W}$, $P=0.01)$ resulting in $53 \%$ greater total work done in the INT compared to CON (71.2 \pm 7.3 vs. $46.3 \pm 2.7 \mathrm{~kJ}$, $P=0.01)$. Peak blood lactate concentration was higher $(P=0.04)$ following INT compared to CON (19.2 \pm 1.0 vs. $17.4 \pm 2.1 \mathrm{mmol} \mathrm{L}^{-1}$, respectively).

\section{AMPK activation}

Phosphorylation of $\mathrm{AMPK}^{\mathrm{Thr} 172}$ increased $(P=0.011)$ 1.6- and 1.3-fold immediately following INT and CON, respectively, before returning to baseline at $3 \mathrm{~h}$ post-exercise (Fig. 2). The magnitude of phosphorylation immediately post-exercise was not different between protocols $(P=0.347)$.

\section{mRNA expression}

There was an increase in mRNA expression of PGC- $1 \alpha$ (5.5- vs. 7.0-fold, $P<0.01$ ) and VEGF (4.3- vs. 3.5-fold, $P=0.02$ ) from pre to $3 \mathrm{~h}$ post-exercise in CON and INT, respectively, the magnitude of which were not different between trials (Fig. 3). HIF-1 $\alpha$ mRNA expression increased (1.5- vs. 2-fold, $P=0.04$ ), and there was a trend for MMP-9 mRNA expression (1.4 vs. 1.3-fold, $P=0.06$ ) to increase from pre to $3 \mathrm{~h}$ post-exercise in CON and INT, respectively, the magnitude of which were not different between trials (Fig. 4). There was no change in eNOS mRNA expression $(P=0.6)$ in either CON or INT (Fig. 4).

\section{Discussion}

This study has demonstrated that low-volume interval and continuous 'all-out' sprint cycling, both totalling $2 \mathrm{~min}$ in duration but differing in total work done, induce 

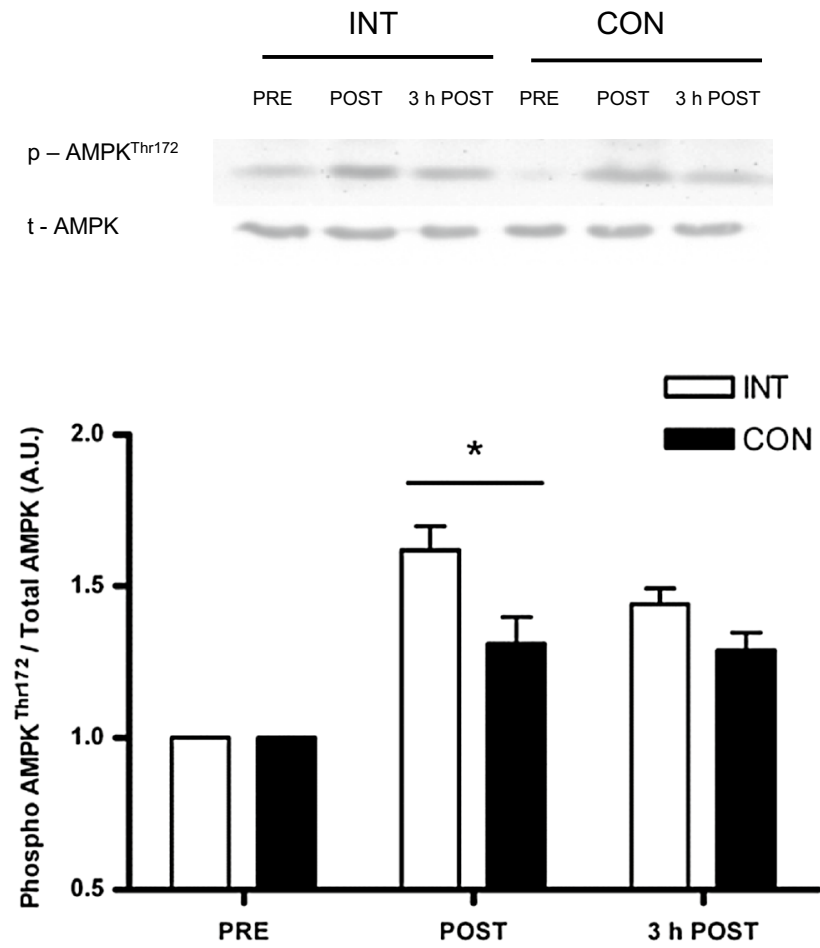

Fig. 2 Phosphorylation of AMPK ${ }^{\text {Thr172 }}$ expressed relative to total AMPK immediately before (PRE), after (POST) and $3 \mathrm{~h}$ after $(3 \mathrm{~h}$ POST) the INT and CON protocols. Representative Western blots above figure. $p$ phosphorylated; $t$ total. Each participant's PRE values have been normalised to 1 , and thus, POST and $3 \mathrm{~h}$ POST values are expressed as fold change relative to PRE values. Values are mean $\pm \mathrm{SE}(n=8)$. *Significant difference from PRE and $3 \mathrm{~h}$ POST $(P<0.05)$

comparable AMPK phosphorylation and increases in PGC- $1 \alpha$, VEGF and HIF- $1 \alpha$ mRNA expression in trained individuals.

The similar increases in AMPK phosphorylation observed immediately after both protocols in the present study are consistent with those previously reported in trained (Yeo et al. 2010; Little et al. 2010) and untrained (Gibala et al. 2009; Little et al. 2011) human muscle after various cycling protocols. The capability of INT and CON to induce comparable acute cell signalling responses to each other, despite $53 \%$ more work being performed in INT, and similar magnitudes of increase to that observed after traditional high-volume endurance training appears related to the 'all-out' nature of the exercise. This possibly reflects the rapid and significant depletion of ATP and muscle glycogen content that occurs in all fibre types and in particular type II muscle fibres during 'all-out' sprint exercise (Greenhaff et al. 1994; Bogdanis et al. 1996; Hargreaves et al. 1998; Karatzaferi et al. 2001). Indeed, the highly glycolytic type IIX fibres display the greatest basal and exercise-induced increases in AMPK phosphorylation (Lee-young et al. 2009) and the high rates
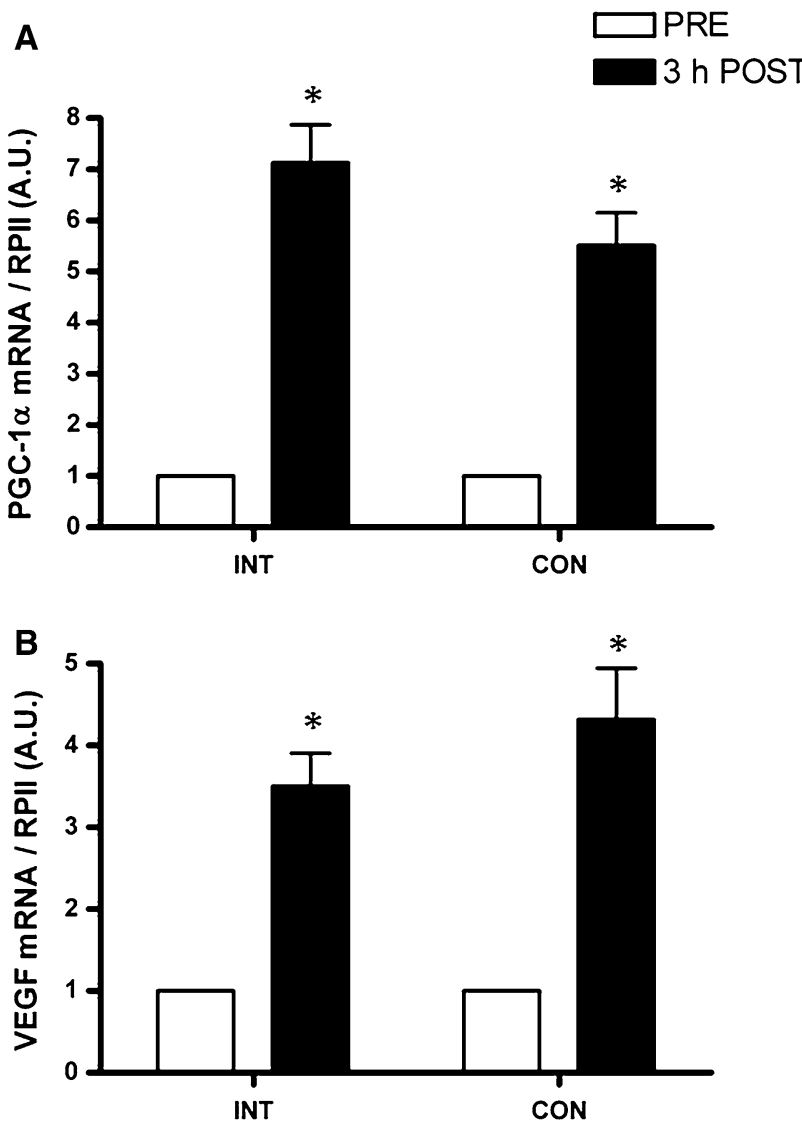

Fig. 3 PGC-1 $\alpha$ (a) and VEGF (b) mRNA expression immediately before (open bars) and at $3 \mathrm{~h}$ after (closed bars) the INT and CON protocols normalised to RPII mRNA content and expressed relative to PRE. Values are mean $\pm \mathrm{SE}(n=8)$. *Significant difference from PRE $(P<0.05)$

of glycogenolysis observed during this type of exercise (Hargreaves et al. 1998) is likely to play a role given the importance of muscle glycogen in regulating AMPK activity (Wojtaszewski et al. 2003; Yeo et al. 2008; Philp et al. 2012).

In accordance with the role of upstream AMPK activation in regulating PGC-1 $\alpha$ (Jäger et al. 2007), the similar fold changes in PGC- $1 \alpha$ mRNA observed at $3 \mathrm{~h}$ after INT and $\mathrm{CON}$ are consistent with magnitudes and time courses previously reported in response to cycling and running in trained (Little et al. 2010; Psilander et al. 2010) and untrained (Gibala et al. 2009; Egan et al. 2010; Bartlett et al. 2012) individuals. Whilst our data supports previous observations (Gibala et al. 2009), we also provide novel data that a single 2 min continuous 'all-out' effort provides an equal stimulus for PGC- $1 \alpha$ expression. Like AMPK, PGC- $1 \alpha$ mRNA abundance is increased in an intensitydependent manner in the hours after exercise, (Egan et al. 2010; Tobina et al. 2011). Increases in PGC- $1 \alpha$ protein content, however, typically occur in the days following 

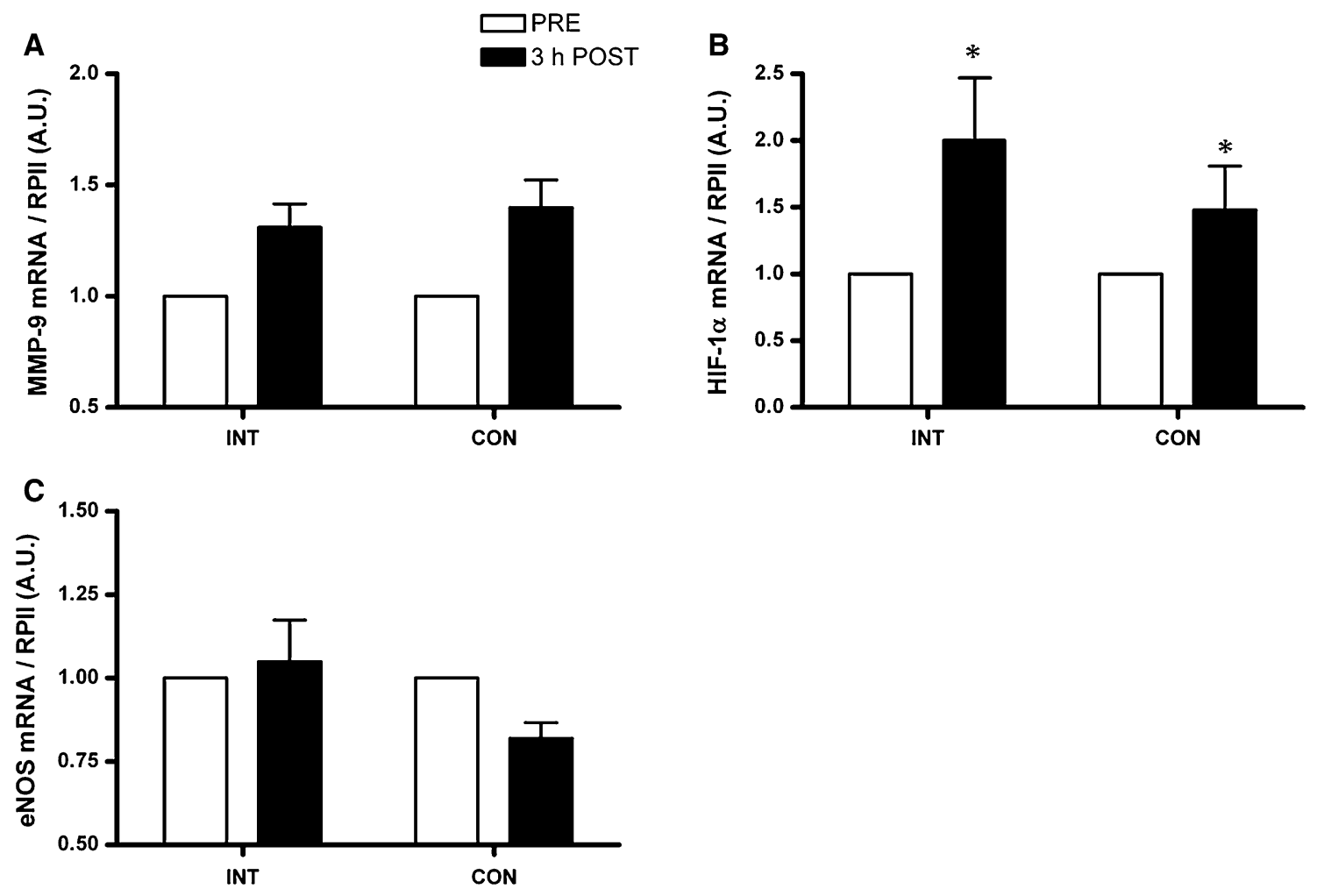

Fig. 4 MMP-9 (a), HIF-1 $\alpha$ (b) and eNOS (c) mRNA expression immediately before (open bars) and at $3 \mathrm{~h}$ after (closed bars) the INT and CON protocols normalised to RPII mRNA content and expressed

relative to PRE. Values are mean $\pm \mathrm{SE}(n=8)$. ${ }^{*}$ Significant difference from PRE $(P<0.05)$

exercise (Baar et al. 2002), probably as a result of cumulative transient increases in mRNA transcripts encoding new protein after successive training bouts (Perry et al. 2010). Further research is required to determine whether both protocols used here would result in comparable PGC-1 $\alpha$ protein increases after an identical number of successive training sessions in both trained and untrained individuals.

PGC- $1 \alpha$ is implicated in a signalling cascade that results in the induction of VEGF (Chinsomboon et al. 2009; Geng et al. 2010), the most important angiogenic growth factor, integral to both longitudinal splitting and sprouting angiogenesis (Olfert et al. 2010; Egginton 2011). It is possible that PGC- $1 \alpha$ played a role in increasing the VEGF mRNA expression observed after both 'all-out' exercise protocols given the regulation of PGC- $1 \alpha$ by post-translational modifications (i.e. phosphorylation and deacetylation) (Puigserver et al. 2001; Jäger et al. 2007). The similar magnitudes of VEGF mRNA increase that we report here are consistent with those observed in the early hours of recovery after acute exercise of varied intensities and durations (Gustafsson et al. 1999; Jensen et al. 2004b; Hoier et al. 2012, 2013b), and to our knowledge are the first reported in response to both interval and continuous 'allout' cycling. Although clearly important, it remains to be

fully established whether VEGF mRNA is increased during recovery from exercise primarily to replenish secreted VEGF protein or is in fact vital to trigger VEGF secretion.

Distinct angiogenic phenotypes occur as a result of exposure to different stimuli which are affected by the mode and intensity of exercise (Egginton 2011). HIF-1 $\alpha$ is a key regulator of the tissue to hypoxia, and thus, metabolic stress (Semenza et al. 2006; Semenza 2006), during which it is stabilized and functions in regulating angiogenesis through targeted activation of VEGF in human skeletal muscle (Lee et al. 2004; Ameln et al. 2005). Acute exercise results in an increase in skeletal muscle HIF-1 $\alpha$ mRNA expression provided that the exercise intensity is sufficient or the tissue is exposed to a hypoxic stimulus (Vogt et al. 2001; Zoll et al. 2006). Thus, the comparable increases in HIF- $1 \alpha$ mRNA expression observed in the early recovery after exercise in the present study may tentatively suggest INT and CON provide a similar stimulus for hypoxia-mediated angiogenesis. Neither of the protocols used here increased eNOS mRNA which has been implicated in high-shear stress mediated angiogenesis (Egginton 2009). However, there was a trend $(P=0.06)$ in the present study for comparable increases in MMP-9 mRNA after INT and CON. MMP-9 is activated in response to muscle overload or mechanical stretch during 
contractions and plays a role in initiating proteolysis of the endothelial cell (EC) basement membrane, thus facilitating EC migration and the formation of new capillaries (Egginton 2009). Increased MMP-9 mRNA expression has previously been observed $2 \mathrm{~h}$ into recovery from moderate intensity endurance exercise in healthy human skeletal muscle (Rullman et al. 2007, 2009) and such transcriptional activation appears important in the regulation of MMP-9 activity (Van den Steen et al. 2002).

The present study is not without limitations. Notably, exercise-induced changes in muscle glycogen content, protein expression reflective of mitochondrial biogenesis and angiogenesis, and measures of angiogenic protein secretion into the circulation were not assessed in the present study. Indeed, although previous studies have demonstrated that the acute angiogenic response can help to inform the magnitude of capillary growth with training (Hellsten et al. 2008; Høier et al. 2010; Hoier et al. 2012), temporal factors relating to the timing and number of biopsies, as well as the training status of the examined muscle, need to be considered when predicting chronic adaptations based on transient molecular responses to acute exercise. Intermittent high-intensity exercise has been previously shown to induce greater elevations of angiogenic growth factors than moderate intensity continuous exercise; however, the latter has been demonstrated to result in greater acute elevations in interstitial levels of VEGF (Hoier et al. 2013a). Moreover, whilst increased capillarity has been observed after 4 weeks of high-intensity intermittent knee extensor exercise in young healthy individuals (Jensen et al. 2004a), others have provided data suggesting high-intensity intermittent training, provides a weak stimulus for capillary growth in a similar population (Hoier et al. 2013a). Although it is plausible from our acute data that trained skeletal muscle exposed to repeated bouts of INT and CON over time would promote comparable increases in mitochondrial biogenesis and capillarity further work is required to directly assess this. Finally, future work should also consider whether this 2 min all-out effort repeated over a period of time has the capacity to improve overall fitness. Cochran et al. (2014) have recently demonstrated in untrained individuals that whilst 'all-out' SIT and work-matched continuous cycling ( 4 min) induce similar acute cell signalling responses, when performed regularly over a 6 week training regime, the continuous protocol did not augment the maximal activity or protein content of mitochondrial markers as has been observed after a similar exposure to SIT in earlier work by this group (Gibala et al. 2006; Burgomaster et al. 2008). Thus, in their relatively untrained cohort, the continuous protocol (which should be noted was not 'all-out' in nature as evidenced by the significantly lower mean peak power output attained in this trial in comparison to SIT) was sufficient to increase $\dot{V} \mathrm{O}_{2 \text { peak }}($ Cochran et al. 2014).
In conclusion, low-volume 'all-out' sprint interval and continuous cycling, matched for total exercise duration but not work done, provides an equally potent stimulus to activate cell signalling pathways associated with exercise-induced mitochondrial biogenesis and angiogenesis in trained skeletal muscle. These findings add to existing data demonstrating that in addition to the amount of total work done, the interval/continuous nature of a training session appears to have little effect on the observed cell signalling response. Whilst these data have implications for exercise prescription and implicate exercise intensity as the key driver in regulating adaptation to low-volume exercise, training studies employing similar 'all-out' exercise protocols are warranted to investigate their effects on structural re-modelling, whole body metabolism and exercise performance.

Acknowledgments The authors would like to thank all participants for their effort and commitment during the demanding study period. This project was partially supported by a grant from the English Institute of Sport.

\section{Compliance with ethical standards}

Conflict of interest The authors have no conflict of interest.

Open Access This article is distributed under the terms of the Creative Commons Attribution 4.0 International License (http://creativecommons.org/licenses/by/4.0/), which permits unrestricted use, distribution, and reproduction in any medium, provided you give appropriate credit to the original author(s) and the source, provide a link to the Creative Commons license, and indicate if changes were made.

\section{References}

Ameln H, Gustafsson T, Sundberg CJ et al (2005) Physiological activation of hypoxia inducible factor-1 in human skeletal muscle. FASEB J 19:1009-1011

Baar K, Wende AR, Jones TE et al (2002) Adaptations of skeletal muscle to exercise: rapid increase in the transcriptional coactivator PGC-1. FASEB J 16:1879-1886

Bartlett JD, Hwa Joo C, Jeong T-S et al (2012) Matched work high-intensity interval and continuous running induce similar increases in PGC-1 $\alpha$ mRNA, AMPK, p38, and p53 phosphorylation in human skeletal muscle. J Appl Physiol 112:1135-1143

Bogdanis GC, Nevill ME, Boobis LH, Lakomy HK (1996) Contribution of phosphocreatine and aerobic metabolism to energy supply during repeated sprint exercise. J Appl Physiol 80:876-884

Burgomaster KA, Howarth KR, Phillips SM et al (2008) Similar metabolic adaptations during exercise after low volume sprint interval and traditional endurance training in humans. J Physiol 586:151-160

Cantó C, Auwerx J (2010) AMP-activated protein kinase and its downstream transcriptional pathways. Cell Mol Life Sci 67:3407-3423

Chinsomboon J, Ruas J, Gupta RK et al (2009) The transcriptional coactivator PGC-1alpha mediates exercise-induced angiogenesis in skeletal muscle. Proc Natl Acad Sci USA 106:21401-21406 
Cochran AJR, Percival ME, Tricarico S et al (2014) Intermittent and continuous high-intensity exercise training induce similar acute but different chronic muscle adaptations. Exp Physiol 99:782-791

Cocks M, Shaw CS, Shepherd SO et al (2013) Sprint interval and endurance training are equally effective in increasing muscle microvascular density and eNOS content in sedentary males. J Physiol 591:641-656

Egan B, Carson BP, Garcia-Roves PM et al (2010) Exercise intensitydependent regulation of peroxisome proliferator-activated receptor coactivator- 1 mRNA abundance is associated with differential activation of upstream signalling kinases in human skeletal muscle. J Physiol 588:1779-1790

Egginton S (2009) Invited review: activity-induced angiogenesis. Pflugers Arch 457:963-977

Egginton S (2011) Physiological factors influencing capillary growth. Acta Physiol (Oxf) 202:225-239

Geng T, Li P, Okutsu M et al (2010) PGC-1alpha plays a functional role in exercise-induced mitochondrial biogenesis and angiogenesis but not fiber-type transformation in mouse skeletal muscle. Am J Physiol Cell Physiol 298:C572-C579

Gibala MJ, Little JP, van Essen M et al (2006) Short-term sprint interval versus traditional endurance training: similar initial adaptations in human skeletal muscle and exercise performance. J Physiol 575:901-911

Gibala MJ, McGee SL, Garnham AP et al (2009) Brief intense interval exercise activates AMPK and p38 MAPK signaling and increases the expression of PGC-1alpha in human skeletal muscle. J Appl Physiol 106:929-934

Greenhaff PL, Nevill ME, Soderlund K et al (1994) The metabolic responses of human type I and II muscle fibres during maximal treadmill sprinting. J Physiol 478:149-155

Gustafsson T, Puntschart A, Kaijser L et al (1999) Exercise-induced expression of angiogenesis-related transcription and growth factors in human skeletal muscle. Am J Physiol 276:H679-H685

Hargreaves M, McKenna MJ, Jenkins DG et al (1998) Muscle metabolites and performance during high-intensity, intermittent exercise. J Appl Physiol 84:1687-1691

Hellsten Y, Rufener N, Nielsen JJ et al (2008) Passive leg movement enhances interstitial VEGF protein, endothelial cell proliferation, and eNOS mRNA content in human skeletal muscle. Am J Physiol Regul Integr Comp Physiol 294:R975-R982

Hoier B, Nordsborg N, Andersen S et al (2012) Pro- and anti-angiogenic factors in human skeletal muscle in response to acute exercise and training. J Physiol 590:595-606

Hoier B, Passos M, Bangsbo J, Hellsten Y (2013a) Intense intermittent exercise provides weak stimulus for vascular endothelial growth factor secretion and capillary growth in skeletal muscle. Exp Physiol 98:585-597

Hoier B, Prats C, Qvortrup K et al (2013b) Subcellular localization and mechanism of secretion of vascular endothelial growth factor in human skeletal muscle. FASEB J 27:3496-3504

Høier B, Rufener N, Bojsen-Møller J et al (2010) The effect of passive movement training on angiogenic factors and capillary growth in human skeletal muscle B. Høier, N. Rufener, J. Bojsen-Møller, J. Bangsbo. Y Hellsten J Physiol 588:3833-3845

Jäger S, Handschin C, St-Pierre J, Spiegelman BM (2007) AMPactivated protein kinase (AMPK) action in skeletal muscle via direct phosphorylation of PGC-1alpha. Proc Natl Acad Sci USA 104:12017-12022

Jensen L, Bangsbo J, Hellsten Y (2004a) Effect of high intensity training on capillarization and presence of angiogenic factors in human skeletal muscle. J Physiol 2:571-582

Jensen L, Schjerling P, Hellsten Y (2004b) Regulation of VEGF and bFGF mRNA expression and other proliferative compounds in skeletal muscle cells. Angiogenesis 7:255-267
Karatzaferi C, de Haan A, Ferguson RA et al (2001) Phosphocreatine and ATP content in human single muscle fibres before and after maximum dynamic exercise. Pflügers Arch Eur J Physiol 442:467-474

Lee J-W, Bae S-H, Jeong J-W et al (2004) Hypoxia-inducible factor (HIF-1)alpha: its protein stability and biological functions. Exp Mol Med 36:1-12

Lee-young RS, Canny BJ, Myers DE, Mcconell GK (2009) AMPK activation is fiber type specific in human skeletal muscle : effects of exercise and short-term exercise training. 283-289

Leick L, Hellsten Y, Fentz J et al (2009) PGC-1alpha mediates exercise-induced skeletal muscle VEGF expression in mice. Am J Physiol Endocrinol Metab 297:E92-E103

Little JP, Safdar A, Cermak N et al (2010) Acute endurance exercise increases the nuclear abundance of PGC-1alpha in trained human skeletal muscle. Am J Physiol Regul Integr Comp Physiol 298:R912-R917

Little JP, Safdar A, Bishop D et al (2011) An acute bout of highintensity interval training increases the nuclear abundance of PGC- 1 alpha\} and activates mitochondrial biogenesis in human skeletal muscle. Am J Physiol Regul Integr Comp Physiol 300:R1303-R1310

Livak KJ, Schmittgen TD (2001) Analysis of relative gene expression data using real-time quantitative PCR and the 2(-Delta Delta C(T)) Method. Methods 25:402-408

Olfert IM, Howlett RA, Wagner PD, Breen EC (2010) Myocyte vascular endothelial growth factor is required for exercise-induced skeletal muscle angiogenesis. Am J Physiol Regul Integr Comp Physiol 299:R1059-R1067

Perry CGR, Lally J, Holloway GP et al (2010) Repeated transient mRNA bursts precede increases in transcriptional and mitochondrial proteins during training in human skeletal muscle. J Physiol 588:4795-4810

Philp A, Hargreaves M, Baar K (2012) More than a store: regulatory roles for glycogen in skeletal muscle adaptation to exercise. Am J Physiol Endocrinol Metab 302:E1343-E1351

Pilegaard H, Ordway GA, Saltin B, Neufer PD (2000) Transcriptional regulation of gene expression in human skeletal muscle during recovery from exercise. Am J Physiol Endocrinol Metab 279:E806-E814

Pilegaard H, Saltin B, Neufer PD (2003) Exercise induces transient transcriptional activation of the PGC-1 gene in human skeletal muscle. J Physiol 546:851-858

Psilander N, Niklas P, Wang L et al (2010) Mitochondrial gene expression in elite cyclists: effects of high-intensity interval exercise. Eur J Appl Physiol 110:597-606

Puigserver P, Spiegelman BM (2003) Peroxisome proliferator-activated receptor-gamma coactivator 1 alpha (PGC-1 alpha): transcriptional coactivator and metabolic regulator. Endocr Rev 24:78-90

Puigserver P, Rhee J, Lin J et al (2001) Cytokine stimulation of energy expenditure through p38 MAP kinase activation of PPAR $\gamma$ coactivator-1. Mol Cell 8:971-982

Rullman E, Rundqvist H, Wågsäter D et al (2007) A single bout of exercise activates matrix metalloproteinase in human skeletal muscle. J Appl Physiol 102:2346-2351

Rullman E, Norrbom J, Stromberg A et al (2009) Endurance exercise activates matrix metalloproteinases in human skeletal muscle. $\mathrm{J}$ Appl Physiol 106:804-812

Semenza GL (2006) Regulation of physiological responses to continuous and intermittent hypoxia by hypoxia-inducible factor 1 . Exp Physiol 91:803-806

Semenza GL, Shimoda LA, Prabhakar NR (2006) Regulation of gene expression by HIF-1. Novartis Found Symp 272:2-8 (discussion 8-14, 33-6)

Tobina T, Yoshioka K, Hirata A et al (2011) Peroxisomal proliferatoractivated receptor gamma co-activator-1 alpha gene expression 
increases above the lactate threshold in human skeletal muscle. $\mathrm{J}$ Sports Med Phys Fitness 51:683-688

Van den Steen PE, Dubois B, Nelissen I et al (2002) Biochemistry and molecular biology of gelatinase B or matrix metalloproteinase-9 (MMP-9). Crit Rev Biochem Mol Biol 37:375-536

Vogt M, Puntschart A, Geiser J et al (2001) Molecular adaptations in human skeletal muscle to endurance training under simulated hypoxic conditions. J Appl Physiol 91:173-182

Wojtaszewski JFP, MacDonald C, Nielsen JN et al (2003) Regulation of 5'AMP-activated protein kinase activity and substrate utilization in exercising human skeletal muscle. Am J Physiol Endocrinol Metab 284:E813-E822
Yeo WK, Paton CD, Garnham AP et al (2008) Skeletal muscle adaptation and performance responses to once a day versus twice every second day endurance training regimens. J Appl Physiol 105:1462-1470

Yeo WK, McGee SL, Carey AL et al (2010) Acute signalling responses to intense endurance training commenced with low or normal muscle glycogen. Exp Physiol 95:351-358

Zoll J, Ponsot E, Dufour S et al (2006) Exercise training in normobaric hypoxia in endurance runners. III. Muscular adjustments of selected gene transcripts. J Appl Physiol 100:1258-1266 